Experiments are being carried out for the purpose of discovering some good substitute for glass in mirror making. "Invar" has proved to be too soft, and the fused quartz discs have not been a success. Prof. Hale suggests that speculum metal will be found to answer the purpose better than glass.

Photographs taken with the Snow telescope have proved better than those obtained with the 40-inch refractor at Yerkes, and Prof. Hale states that, from a mechanical standpoint also, the telescope has proved completely successful.

\section{STUDIES ON THE SYNTHESIS OF PEPTIDES} AND PROTEIDS. ${ }^{\mathrm{I}}$

A MONG the many brilliant achievements in synthetic chemistry accomplished by Prof. Emil Fischer during the last quarter of a century, none have surpassed in interest the remarkable series of researches which formed the subject of a recent address to the German Chemical Society.

In reading this address it is impossible to say which commands greater admiration, the author's consummate skill and endless resource in sweeping aside each difficulty as it arose in a most intricate field of experimental inquiry, or his intense and ceaseless activity in producing almost month by month during the past five years a wealth of new knowledge of the very first importance to biological science.

"Whilst our cautious colleagues," says Prof. Fischer, " fear that a systematic study of this group of compounds (the proteids) will be beset with endless difficulties on account of their troublesome physical features, there are others, among whom I count muself, who are more optimistic, and hold that an attempt at least ought to be made with every modern appliance to lay siege to this unconquered citadel; for it is only by a bold attempt that the limitations of our present methods can be adequately gauged."

The success which has so far attended Prof. Fischer's first attack promises a speedy capitulation. The proteids will then be made to deliver up the key to their molecular structure, and the first real advance in biochemistry will have been accomplished.

Although physiological chemistry has done much in the past in the way of classifying the numerous members of the proteid group, in preparing a few members in the crystalline form, in attaching to different individuals different biological functions, and in ascertaining the fundamental changes effected by ferment action, our knowledge of their chemical constitution has up to the present been extremely meagre. Apart from the percentage composition, it is limited mainly to the results of hydrolysis by acids, alkalis, or digestive ferments. When submitted to these agents all proteids yield successively albumoses, peptones, and, finally, amino-acids. Of the nature of the first two we are but little better informed than of that of the proteids themselves.

The study of the amino-acids has been attended with more success, for not only has the structure of the majority of them been ascertained, but many have been prepared synthetically. The following is a list of amino-acids obtained by hydrolysing one or other of the natural proteids :--

Glycine

Alanine

Aninovaleric acid

Leucine

Isoleucine

Phenylalanine

Glutamic acid

Aspartic acid

Cysteine

a-Pyrrolidine carboxylic acid (proline)

Hydroxy-pyrrolidine carboxylic acid (oxypyroline)

Serine ( $\alpha$-amino- $\beta$-hydroxypropionic acid)

Tyrosine

Tryptophane (skatolaminoacetic acid)

Lysine

Arginine

Histidine

Diaminotrihydroxydodecanic acid

Diaminoglutaric acid

Diaminoadipic acid

Hydroxyaminosuccinic acid

Dihydroxyaminosuberic acid

1 Vide Address by Prof. Emil Fischer, "Untersuchungen über Amino. säuren Polypeptide und Proteine" (Berichte der deutschen Chem. Gesell. ago6, xxxix., 530.)

No. I 900, VOL. 73]
It was to the study of these acids-the fragments, so to speak, of the albumin molecule-that Fischer first directed his attention, hoping ultimately by piecing them together to construct the simplest of the albumins. In the synthesis of the monoamino-acids Fischer has added to the methods already known that of brominating the alkyl malonic esters and then converting the corresponding acid into the $\alpha$-bromo-fatty acid, which with ammonia yields the amino-acid. $\mathrm{He}$ has, moreover, devised an ingenious process for resolving the synthetic, and, consequently, inactive compounds into their active components. The amino-acids are such weak acids that they refuse to form crystalline salts with the active alkaloids. By converting them into the benzoyl or formyl derivatives, strong acids are produced which may be easily resolved by the ordinary process of fractionally crystallising the salts of the active bases. The diamino-acids, such as ornithine ( $\alpha \delta$-diaminovaleric acid) and lysine ( $\alpha \epsilon$-diaminocaproic acid), both common products (the former as arginine) of proteid hydrolysis, have also been synthesised by Fischer by adapting Gabriel's reaction in one case and that of Blank in the other. Gabriel's phthalimidopropylmalonic ester, when brominated, gives a monobromo-derivative, which is then hydrolysed and heated to remove one carboxyl group, the resulting compound being phthalimidobromovaleric acid,

$$
\mathrm{C}_{6} \mathrm{H}_{4}\left\langle\mathrm{CO}>\mathrm{CO} \cdot \mathrm{CH}_{2} \cdot \mathrm{CH}_{2} \cdot \mathrm{CH}_{2} \mathrm{CHBr} . \mathrm{COOH}\right. \text {. }
$$

This was converted into the amino-derivative, and by splitting off the phthalyl radical the racemic form of natural ornithine was obtained,

$$
\mathrm{NH}_{2} \cdot \mathrm{CH}_{2} \cdot \mathrm{CH}_{2} \cdot \mathrm{CH}_{2} \cdot \mathrm{CH}\left(\mathrm{NH}_{2}\right) \cdot \mathrm{COOH} \text {. }
$$

The starting point for the preparation of lysine was Blank's $\gamma$-cyanopropylmalonic ester,

$$
\mathrm{CN} . \mathrm{CH}_{2} \cdot \mathrm{CH}_{2}, \mathrm{CH}_{2} \cdot \mathrm{CH}\left(\mathrm{COOC}_{2} \mathrm{H}_{5}\right)_{2} \text {, }
$$

which is converted by nitrous acid into $\alpha$-oximino- $\delta$-cyanovaleric ester,

$$
\text { CN. } \mathrm{CH}_{2} \cdot \mathrm{CH}_{2} \cdot \mathrm{CH}_{2} \mathrm{C}(: \mathrm{NOH}) \cdot \mathrm{COOC}_{2} \mathrm{H}_{5} \text {. }
$$

The latter, on reduction, yields the racemic form of lysine ( $\alpha \epsilon$-diaminocaproic acid). 'The synthesis of hydroxy: acids such as serine of silk fibroin has also been accomplished by applying Strecker's reaction to the hydroxyaldehydes. Thus ammonia converts the cyanhydrin of glycollic aldehyde into the aminocyanhydrin which on hydrolysis yields inactive serine,

\section{$\mathrm{CH}_{2}(\mathrm{OH}) \cdot \mathrm{CHO} \longrightarrow \mathrm{CH}_{2}(\mathrm{OH}) \cdot \mathrm{CH}(\mathrm{OH}) \cdot \mathrm{CN} \longrightarrow$}

\section{$\mathrm{CH}_{2}(\mathrm{OH}) \cdot \mathrm{CHNH}_{2} \cdot \mathrm{CN} \rightarrow \mathrm{CH}_{2}(\mathrm{OH}) \cdot \mathrm{CHNH}_{2} \cdot \mathrm{COOH}$.}

Of no less importance to the solution of the albumin problem have been the new methods furnished by Fischer for the separation and identification of the products of proteid hydrolysis, for a correct knowledge of the varied compounds which compose the albumin molecule must necessarily precede any attempt to effect its synthesis. Foremost among these stands the " ester method." It consists in converting the mixture of amino-acids, obtained on hydrolysis, into the corresponding esters, which are then submitted to fractional distillation under very much reduced pressure (10-15 mm.). The method cannot, however, be conveniently applied to the separation of tyrosine or the diamino-acids, which are treated in a different fashion. Space does not permit of more than a passing reference to the formation of benzoyl, formyl, and $\beta$-naphthalene sulphonyl derivatives, and of the phenyl hydantoins obtained with phenylisocyanate, all of which have been utilised either in the purification or identification of the amino-acids. We must leave this part of the subject in order to follow Prof. Fischer into the more attractive field of constructive research, and examine the plans which he has laid for attacking the synthetic side of the problem. Simply stated, the object he has had in view has been to link together two, three, four, or more molecules of those amino-acids which the proteids yield on hydrolysis, and by varying the combinations to obtain eventually something resembling the peptones or the simplest albumins. To these artificial combinations of 
amino-acids Fischer has given the name of polypeptide, or, according to the number of single amino-acid groups present, di-, tri-, tetra-, \&c., peptide. This view of the constitution of proteid matter, which seemed at the outset of the investigation warranted by the nature of the evidence then forthcoming, received ample justification by the very recent isolation of the first natural dipeptide in the process of hydrolysing silk fibroin. But we are anticipating matters. The first of the polypeptides was obtained by Curtius in 1882 , but as its structure is complex and has only been lately ascertained, we will begin with the simpler members prepared by Fischer.

In Igor Fischer and Fourneau found that glycine anhydride, which, according to Curtius, is formed when glycine ester is heated in aqueous solution, is partly hydrolysed with mineral acids into glycylglycine, the first and simplest of the dipeptides,

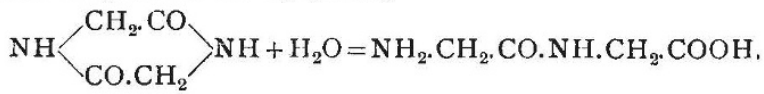

A year later Fischer found that a third amino-acid or peptide group could be linked to the carbethoxy-derivative of glycylglycine (prepared by the action of chloroformic ester on the dipeptide) by heating it with leucine ester, whereby carbethoxyglycylglycyl-leucine ester resulted, which on hydrolysis is converted into the free acid,

\section{$\mathrm{C}_{2} \mathrm{H}_{5} \mathrm{CO}_{2}$. NH.CH${ }_{2}$. CO.NH. $\mathrm{CH}_{2}$. CO.NH.CH $\left(\mathrm{C}_{4} \mathrm{H}_{9}\right) \mathrm{CO}_{2} \mathrm{H}$.}

The next year saw the introduction of a new method for adding fresh links to the peptide chain by the use of thionyl chloride. This effects the conversion of the end carboxyl group into the acid chloride, and it thus became possible by the subsequent action of an amino-ester to add a new peptide group to the molecule. Thus carbethoxyglycylglycine was converted successively into the acid chloride, and then by the action of glycine ester into carbethoxydiglycylglycine ester, and by a repetition of the process into carbethoxytriglycylglycine ester. Similar compounds with different amino-acids were obtained by this reaction. In all of them, however, the carbethoxygroup at the amino end of the chain refused to be removed, and a new method had to be found for preparing the free polypeptides. This was soon forthcoming. In 1903 Fischer and Otto introduced the chloracyl chlorides for the purpose. Glycylglycine ester was first combined with chloracetyl chloride, hydrolysed, and warmed with ammonia, whereby diglycylglycine was formed,

$\mathrm{ClCH}_{2} \cdot \mathrm{COCl}+\mathrm{NH}_{2} \cdot \mathrm{CH}_{2} \cdot \mathrm{CO}, \mathrm{NH} \cdot \mathrm{CH}_{2} \cdot \mathrm{COOR}=$ $\mathrm{ClCH}_{2} \cdot \mathrm{CO}, \stackrel{\mathrm{NH}}{\mathrm{C}} \mathrm{CH}_{2} \cdot \mathrm{CO}, \mathrm{NH} . \mathrm{CH}_{2} \cdot \mathrm{COOR}+\mathrm{HCl}$.

$\mathrm{ClCH}_{2} \cdot \mathrm{CO}, \mathrm{NH} . \mathrm{CH}_{2} \cdot \mathrm{CO}, \mathrm{NH} \cdot \mathrm{CH}_{2} \cdot \mathrm{COOH}+\mathrm{NH}_{3}=$ $\mathrm{NH}_{2} \cdot \mathrm{CH}_{2} \cdot \mathrm{CO}, \mathrm{NH} \cdot \mathrm{CH}_{2} \cdot \mathrm{CO}, \mathrm{NH} \cdot \mathrm{CH}_{2} \mathrm{COOH}+\mathrm{HCl}$

This method proved extremely fruitful, and led to the production of a variety of di-, tri-, tetra-, and pentapeptides.

It will be easily conceived how the methods just described afford the means of lengthening the peptide chain at either end. In the one case an $\alpha$-chloro- or bromoacyl chloride is added to the amino-group at one end, or, at the other, the carboxyl group is converted into the acid chloride, for which purpose thionyl chloride has since been replaced by phosphorus pentachloride dissolved in acetyl chloride. In the first case the action of ammonia, in the second that of an amino-acid or another peptide (the ester is not necessary) in presence of alkali, produces the new peptide. By combining the two processes, hexa- and heptapeptides giving the biuret reaction have been formed from diglycylglycine, and Prof. Fischer confidently predicts the synthesis of still longer chains. In the present year Fischer has also found that two molecules of the methyl ester of diglycylglycine can by heating be combined into the ester of pentaglycylglycine, which yields the hexapeptide on hydrolysis.

If the proteids themselves and the amino-acids to which they give rise comprised optically inactive members, the experimental difficulties in the way of synthesis might be looked upon as approaching solution; but few of the natural products are inactive, and the question of preparing by artificial means active polypeptides must be No. I900, VOL. 73] faced. This part of the problem has not been neglected. By resolving the amino-acids into their active constituents before linking them together, or by submitting certain inactive members to the selective fermentation of pancreatic juice (for trypsin acts upon some of the polypeptides as it does on proteids), active polypeptides have been obtained.

In addition to the action of trypsin, the polypeptides exhibit many characteristics of the simpler proteids; they are for the most part soluble in water; especially is this the case where the peptide is composed of different aminoacids; they are insoluble in alcohol, and many of the higher members give the "biuret" reaction. Like the proteids, also, they are quickly and completely hydrolysed by strong hydrochloric acid into amino-acids; the action of dilute hydrochloric acid and caustic alkalis is, on the other hand, very slow.

The concluding sections of the address will appeal more especially to physiologists, for they deal with the products of hydrolysis of the proteids themselves. Space will not permit of more than a passing reference to them; the reader who is interested in the products obtained by the action of pancreatic juice or the combined action of pepsin, hydrochloric acid, and pancreatin must refer to the original memoir. It may, however, be stated that pancreatin yields, in addition to numerous monoamino-acids, a product which does not give the biuret reaction, but shows a certain resemblance to the artificial polypeptides, and breaks up on hydrolysis with acids into alanine, leucine, glutamic and aspartic acid, as well as proline and phenylalanine. By the successive pepsin and pancreatin digestion the amount of this polypeptide body is diminished, but in its place proline and phenylalanine appear.

As many of the commoner forms of proteid matter behave in this way, Fischer concludes that proline is an actual constituent of the proteid molecule. For similar reasons he includes tyrosine, leucine, alanine, tryptophane, \&c., which always appear in the pancreatic digestion of albumin, a view which is supported by the action of pancreatic juice on the artificial polypeptides containing these groups. But of all the facts which point to the polypeptide nature of the albumins, the most convincing is Fischer and Abderhalden's latest discovery of a dipeptide in silk fibroin, which they have identified as glycyl-dalanine. The method of preparation is interesting, because it introduces the new principle of combining acid with pancreatic hydrolysis. The silk fibroin is first digested with 70 per cent. sulphuric acid for several days at $18^{\circ}$, then diluted with water, the acid removed with baryta, and the liquid evaporated and submitted to the action of pancreatic juice for eight days. The tyrosine which had then separated was removed, and the esters of the aminoacids were formed in the usual way and heated under reduced pressure at $65^{\circ}$ to remove the alcohol and a little glycine and alanine ester.

From the syrupy residue dissolved in alcohol and saturated with ammonia gas (to convert the dipeptide ester into the diketopiperazine), a crystalline precipitate of glycyl alanine anhydride slowly separated. Fischer sees in this discovery a near prospect of obtaining the most important constituents of the natural peptones, and even of the albumoses, and of reproducing them artificially. "But the problem of reproducing true albumins," says Fischer, " is of far greater difficulty, for their reconstruction from the first products of hydrolysis (peptones and albumoses) will require entirely novel methods, and when these are found their application will probably be a laborious process. One may therefore ask the question whether the eventual success will compensate for the labour expended. This depends, in my opinion, on the profit which biological research can derive from it, and this, again, on the manner in which the synthesis has been accomplished. For such a synthesis may be compared to a tourist who rushes through a country in an express train and sees nothing. It is otherwise if the synthesis is constrained to advance slowly and to construct the molecule step by step. It is then like a traveller journeying on foot, who notes every feature of the road, and tries each side-path before the right one is found. He not only learns every inch of the country, but understands the nature of its inhabitants. $\mathrm{He}$ knows his way and can direct others. I can only look 
upon it, therefore, as a piece of good fortune that synthesis demands the creation of countless new methods of construction, separation, and recognition, and the study of hundreds of intermediate products before the proteids themselves can be reached. For these methods not only serve in the end to produce all the natural albumins, but bring to light many more which may eventually serve to explain the remarkable changes which certain proteids effect in the form of ferments and toxins.

J. B. C.

\section{THE PROTECTION OF BIRDS.}

$\mathrm{IN}$ its report for 1905 , the Royal Society for the Protection of Birds directs attention to the circumstance that the year under review is the first during which it has enjoyed the privilege of a Royal Charter. Reference is also made to the importance of last year's ornithological congress in connection with the recognition of the great principle that bird-protection is an international affair, and that, in the case of migratory species, it is of little use to adopt protective measures in this country if indiscriminate slaughter is carried on abroad. It is, moreover, also pointed out that we are by no means free from reproach in this matter even at home, as is exemplified by the instance of a honeybuzzard which was killed and mounted in the Isle of Wight, although such procedure would have been illegal in Hampshire. The progress of bird-protection in India is referred to with approval; but it is stated that further international action is required in connection with the trade in "osprey-plumes."

Simultaneously with the report of the English Society for the Protection of Birds, we received those of the kindred American body, the National Association of Audubon Societies, for 1904 and 1905 . The former of these contains a history of the "Audubon movement" in the United States by Mr. W. Datcher, the president of the association, and also the results of a special effort for the protection of water-birds, made possible by a fund at the disposal of the association. In the report for 1905 the president has to congratulate the association on its first year's working as a corporate organisation, the incorporation having largely augmented its power for good. After referring to the cordial relations existing between the association and foreign bodies the work of which is of a similar nature, the president directs special attention to correspondence relating to the urgent need of protection for the extensive bird-colonies in certain islands in the Pacific. Special efforts are being made to enlist the interest of the general public in bird-protection by means of exquisitely illustrated leaflets (of which we have received a sheaf) descriptive of some of the rare and more interesting birds. In the case of the cardinal and so-called American goldfinch, the illustrations are coloured.

\section{THE PLACE OF POLYTECHNICS IN}

THOSE of you who know what you are doing here and know what is being done in other places must feel that we are at a very interesting, almost a critical, time from an educational point of view. We may be said, indeed, to be at the beginning of a new renaissance--a new birth of learning, just in the same way that our forbears, A.D. 1000 up to A.D. 1200, were in the forefront of that first renaissance. But the trouble is that the dark ages did not cease then, for we have had a dark age since, and it is to correct this second dark age that this new birth is necessary. Now what did the inhabitants of Europe do at that first renaissance? They kept on the schools which had been brought down by the different rulers, the different church authorities, from the time of the Roman Empire. The Roman schools, judging from what the Romans did from Scotland to the south end of the Red Sea, must have dealt with the science of the time, and that perhaps is the reason that the earliest universities always included "the nature of things" in their curricula. A modern public schoolmaster might not think their educa-

1 Extracts from an Address delivered at the Borough Polytechnic Institute on December 4, rgo5, by Sir Norman Lockyer, K.C.B., F.R.S. tion complete because Latin and Greek were the modern languages then, and the students were taught no dead ones; but, be this as it may, at the renaissance they insisted upon the teaching of Latin, because then everybody who was anybody spoke Latin-it was the lingua franca of Europe-and not to speak Latin was to belong to the corps of the deaf and dumb. Secondly, they had to learn Greek, because the movers in the educational world at that time were chiefly doctors, and they had learned all they could about doctoring and surgery from bad Latin rranslations of bad Arabic translations of the Greek authorities, so that when the Greek manuscripts became available all the world was agog to learn Greek in order chiefly that they might learn medicine and surgery. Now, I want to point out to you that in this we had education founded absolutely and completely upon the crying needs of the time. Very good. Then if we are going to do anything like that in our new renaissance, what ought we to do if we are to follow precedent? We must arrange our education in some way in relation to the crying needs of the time. The least little dip into the history of the old universities will prick the bubble of classical education as it is presented to us to-day. Latin was not learned because it had the most magnificent grammar of known languages. Greek was not learned in consequence of the transcendental sublimity of ancient Greek civilisation. Both these things were learned because people had to learn them to get their daily bread, either as theologians or doctors or lawyers, and while they learned them the "nature of things " was not forgotten.

Now what is the problem of to-day? We are in a world which has been entirely changed by the advent of modern science, modern nations, and modern industries, and it is therefore perfectly obvious that if we wish to do the best for our education it must be in some relation to those three great changes which have come on the world since the old days. Remember, in the old days there was no experimental philosophy, there was no steam, there was little relation practically between the ordinary lives of the people and the phenomena, or, at all events, the working of the world of nature around them. But with us all our life, the poorest life, the richest life, the country life, the town life, if it is to be lived properly and wholesomely, has to be lived in the full light of modern science; we have to know exactly the best thing to do and why we should do it. The problem before us to-day, if it be the same problem that was before those old peoples, the problem, that is to say, of learning everything we can from those around us in other nations, must drive us to the study of modern languages, just as the modern world conditions drive us to modern science, so that there, I think, we have an answer to those who may ask of us: What changes are you going to make in modern education if you are going to have the best possible education? First of all, we have the fact that we are bound, if we follow precedent, to deal with those things which are of importance from the present point of view. Latin is no longer the lingua franca of Europe, and we have better guides in science and philosophy than Aristotle. A question which arises when we go on to consider this matter is a very simple one: Is it worth while bothering about education? Is it worth while troubling to inquire what the old renaissance did or the new renaissance ought to do? Now there we approach a question in which the world is certainly very much wiser than it was a few years ago. Thirty or forty years ago, I am sorry to say, in this country practically nobody cared anything whatever about education, at all events about the education of the people, and the trouble with us now-the trouble that we shall have to take years to get over-is that in Germany that question was settled as early as the time of Luther, who insisted that it was the duty of all communities to look after the education of their children as well as the building of bridges and the making of roads. Now I think it is generally accepted, both in this country and in others, that whether the citizens of a State are educated or not is a matter of absolutely supreme importance, and when I say " educated "I mean educated morally and physically as well as intellectually. It is no longer merely the concern of the child or of the child's parent. It is acknowledged to be the only true foundation for a 